\section{STEM Is Not a Monolith: A Preliminary Analysis of Variations in STEM Disciplinary Cultures and Implications for Change}

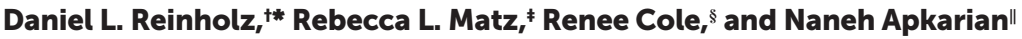

${ }^{\dagger}$ Department of Mathematics and Statistics, San Diego State University, San Diego, CA 921827720; "Hub for Innovation in Learning and Technology, Michigan State University, East Lansing, MI 48824; "Department of Chemistry, University of lowa, lowa City, IA 52242-1294; "Center for Research on Instructional Change in Postsecondary Education, Western Michigan University, Kalamazoo, MI 49008-5288

\begin{abstract}
Research suggests that science, technology, engineering, and mathematics (STEM) departments are a productive unit of focus for systemic change efforts. In particular, they are relatively coherent units of culture, and cultural changes are critical to creating sustainable improvements. However, the STEM disciplines are often treated as a monolith in change literature, and unique aspects of these different disciplinary cultures-and consequences for change efforts-remain somewhat underdeveloped. This exploratory study focuses on similarities and differences among STEM disciplinary cultures, drawing on data gathered from scholars in discipline-based education research who attended two sessions at the 2017 Transforming Research in Undergraduate STEM Education conference. Our analyses of these data help begin to characterize disciplinary cultures using the theoretical lens of four frames: structures, symbols, power, and people. We find preliminary evidence for both similarities and differences among the cultures of STEM disciplines. Implications for change efforts and future directions for research are discussed.
\end{abstract}

\section{INTRODUCTION}

This exploratory study reports on findings from the 2017 Transforming Research in Undergraduate STEM Education (TRUSE) conference, designed to foster information sharing and cross-disciplinary collaboration among faculty in discipline-based education research (DBER; National Research Council [NRC], 2012). The conference was organized to support discussion about systemic change in teaching and learning, an elusive goal for undergraduate education in science, technology, engineering, and mathematics (STEM) disciplines. For instance, a recent analysis of more than 100 change efforts underscores the difficulty of achieving such change (Henderson et al., 2011) and highlights the need for more contextualized theories about how change works in STEM departments. Further, this analysis showed that most efforts employ a single change strategy. Borrego and Henderson (2014) extended this work by proposing eight change strategies that can be used in various combinations to more effectively promote institutional change.

Decisions that guide a change effort should be informed by an understanding of the context in which change is being promoted. Change agents, both those in DBER and otherwise, are therefore faced with a complex puzzle, wherein they must understand and leverage the context of the department and institution to make meaningful change. We define a change agent as anyone who is dissatisfied with the status quo and who is seeking to implement reforms in a given context (Dunne and Zandstra, 2011). A change agent in a postsecondary STEM education context could be a curriculum developer, faculty member, department chair, administrator on campus, or any other relevant actor who is working to change instructional practice. Here, we
CBE Life Sci Educ December 1, 2019 18:mr4 DOI:10.1187/cbe.19-02-0038

Authors' contributions: D.L.R. conceptualized this article and was responsible for creating the first draft. R.L.M. and R.C. led data analysis. All authors discussed the analyses as a team and also contributed to the writing and revision process. *Address correspondence to: Daniel L. Reinholz (daniel.reinholz@sdsu.edu).

(C) 2019 D. L. Reinholz et al. CBE-Life Sciences Education (C) 2019 The American Society for Cell Biology. This article is distributed by The American Society for Cell Biology under license from the author(s). It is available to the public under an Attribution-Noncommercial-Share Alike 3.0 Unported Creative Commons License (http://creativecommons.org/licenses/ by-nc-sa/3.0)

"ASCB®" and "The American Society for Cell Biology ${ }^{\circledR}$ " are registered trademarks of The American Society for Cell Biology. 
contribute to the study of change in higher education by focusing on comparisons among disciplinary cultures. This preliminary study provides grist for future research, and we outline possible directions for such research in our discussion. Our analyses were guided by the overarching goal of understanding how similarities and differences between STEM disciplinary cultures may be consequential for educational change. The TRUSE conference was a useful context for our preliminary explorations, because it had the explicit goal of bringing together DBER researchers from different disciplines.

Culture is a cohesive force that brings stability to a group's interactions (Schein, 2010). For example, while teaching loads, service expectations, meeting norms, and disciplinary identity may differ across departments, they tend to be relatively consistent within a single department. Thus, an essential step toward designing effective change efforts is a deep understanding of departmental culture (NRC, 2012; Kezar, 2014; Froyd et al., 2017; Stanford et al., 2017). If culture is ignored, given its stabilizing properties, changes are likely to result in quick fixes that shortly revert back to the status quo rather than sustainable transformation (Reinholz et al., 2019b). Though departmental culture is not static, if the current culture and norms in a department are ignored, change efforts are less likely to result in sustained adoption of the intended instructional practices (Henderson et al., 2015; Stanford et al., 2017).

Coined in the 1990s, the acronym "STEM" reflects commonalities among this set of disciplines that, for instance, distinguish them from the humanities (cf. Becher, 1994). This focus on commonalities is reflected in the many calls to improve STEM education broadly (e.g., President's Council of Advisors on Science and Technology [PCAST], 2012), but it seems likely that change theories will be developed that are only modestly contextualized if individual STEM disciplines are not taken into consideration. In this paper, we add nuance to the view of STEM as a monolithic culture by drawing attention to some aspects of the unique disciplinary cultures in four STEM disciplines (biology, chemistry, mathematics, and physics). To elaborate on differences and similarities in these disciplinary cultures, we draw on the four frames model of organizational culture (Bolman and Deal, 2008; Reinholz and Apkarian, 2018). This model allows us to attend to differences in the organizational cultures of different STEM disciplines, so we are able to describe aspects of departmental operations that may be consequential for change. Recognizing that departments are embedded within postsecondary institutions (e.g., Lee, 2007; Laursen, 2016), we acknowledge that some departmental differences may result from particular institutional norms rather than disciplinary culture.

Guided by these theoretical frameworks, we explored the results of two sessions at the TRUSE conference. The data collected from these sessions were intended to provide formative feedback to the session organizers, but we chose to analyze them more deeply, because they provide insights from DBER scholars across a subset of STEM disciplines unpacking their disciplinary cultures. Drawing on these data, we begin to explore the following research question: How are the cultures of individual STEM disciplines both similar and different? Here, we offer a preliminary report of similarities and differences observed across four disciplines as well as a collection of questions that researchers may draw on to understand the local culture within a department. We also discuss emergent findings from the sessions with regard to aspects of culture that appeared to be a function of institution instead of discipline. This work is relevant for those engaged in DBER scholarship to understand change and change agents seeking to put theory into practice.

\section{BACKGROUND}

The need for systemic change in STEM departments is now recognized by a number of key institutions across the international landscape (e.g., Niss, 2011; PCAST, 2012; Commonwealth of Australia, 2015; European Parliament, 2015). Alongside these calls, the quantity and quality of DBER research has increased significantly, resulting in a host of findings regarding students' conceptual understandings, learning processes, instructional strategies, and programs that support diversification and success in undergraduate STEM (e.g., NRC, 2012; Docktor and Mestre, 2014; Freeman et al., 2014; Talanquer, 2014; Henderson et al., 2017). Large-scale transformation of undergraduate educational experiences in STEM has not, however, been realized (e.g., Blair et al., 2018; NRC, 2012; Stains et al., 2018). This is in part because change agents frequently rely on simplistic and implicit models for change (Borrego and Henderson, 2014) that are largely ineffective (Henderson et al., 2011) and unlikely to result in broad, desired changes (Fairweather, 2008; Austin, 2011; Kezar, 2011; Froyd et al., 2017). DBER scholars have begun to draw on organizational science as a means to translate theory into practice, with a focus on organizational culture and its relationship to change. There has been a rise in calls for the DBER community to engage in efforts to enact change in their respective STEM fields (e.g., Singer et al., 2013; Docktor and Mestre, 2014; Sohoni et al., 2017), and an understanding of the impact and variation of STEM cultures on the change process is critical for supporting this work.

Change takes place at many different scales, ranging from individual faculty (Steinert et al., 2006) to entire postsecondary institutions (Elrod and Kezar, 2015). In the middle of this range is work that focuses on departments (e.g., American Association for the Advancement of Science, 2011; Association of American Colleges and Universities, 2014). We focus on departments as the key unit of change because of their relative internal coherence in terms of policies (e.g., teaching loads and committee structures), norms, disciplinary content, and faculty interactions. Moreover, individual departments are generally responsible for designing their courses (Quardokus and Henderson, 2015) and socializing their students into their disciplines (Lee, 2007; Lee et al., 2007), so efforts to impact education in, for example, chemistry can be easily located within a chemistry department. Departments are relatively coherent units of culture and, given the stabilizing function of culture, they are important leverage points for sustainable change (Reinholz et al., 2019b).

Although departments are relatively consistent in their disciplinary cultures, subdisciplines exist within departments that may have different subcultures. For example, a mathematics department may have scholars of pure mathematics, applied mathematics, and mathematics education. While each of these groups will have a strong mathematics identity and emphasis on logical argumentation, pure mathematicians are most likely to prize proof above other groups, while applied 
mathematicians may focus more on the practical implications of research. Similar subgroups exist in other disciplines.

There is no universally accepted definition of culture in the organizational change literature (Langan-Fox and Tan, 1997). Nonetheless, the various definitions do agree on some of the basic issues: 1) culture is stable and resists change, 2) it is often taken for granted and works implicitly, 3) it is given meaning by an organization's members, and 4) it consists of a set of shared understandings (Langan-Fox and Tan, 1997). To move beyond this general characterization, we draw on the four frames model to define culture as follows (Bolman and Deal, 2008; Reinholz and Apkarian, 2018): Culture is a historical and evolving set of structures and symbols and the resulting power relationships between people. These four areas-structures, symbols, power, and people-are four frames for understanding the culture of a department.

Structures are formal roles, responsibilities, practices, and routines. These structures organize who interacts and how. For example, department meetings, committees, and peer observations are relatively stable structures in most departments that help faculty members achieve their collective responsibilities. However, how these structures are enacted depends on a particular context (e.g., a department might meet monthly in meetings, or only once per semester; voting could be based on a majority or consensus). In this way, how structures are enacted relies on other aspects of departmental culture, such as symbols.

Symbols relate to beliefs and meaning-making. To make meaning, individuals draw on cultural symbols, artifacts, language, myths, and values. For instance, faculty members use language that is discipline specific (e.g., emergent systems in biology and deductive arguments in mathematics), and there may be particular stories or events that are crucial to the discipline, such as Einstein's development of the theories of relativity. This variation in symbols of a department influences how individuals in the department reason and what anchor points they have for conversations.

People are the members of a department, with individual goals, agency, needs, and identities. For example, tenure-track faculty, non-tenure track instructors, graduate students, and staff have different needs and goals. Finally, power mediates interactions through status, positioning, and political coalitions. In this way, the changes taken up in a department depend on the sanction of individuals and committees who have the power for decision making.

In addition, culture is historical and evolving; it is grounded in the past and will continue to change in the future; that is, effective supports for enacting change within a given department may change with time. Furthermore, we recognize that culture is semicoherent, with each individual in a department experiencing culture through these four frames somewhat differently than other department members, resulting in individual perspectives and subcultures within a department. Despite these idiosyncrasies and individual experiences within a department, individuals share many commonalities resulting from the disciplinary, institutional, and department-specific factors within that department.

Our work in this exploratory study focuses on discipline, but here we briefly acknowledge the importance of other factors. Departmental culture also depends on institutional context
(Lee, 2007). Institutions differ in a variety of ways, among them access (Chetty et al., 2017), religious identity (Mixon et al., 2004), funding structures (Levin, 2005), and support for students from diverse backgrounds (Hurtado et al., 2011). Individual institutions are idiosyncratic and have their own policies and norms, such as formal faculty positions and grading structures (Warren, 1971). Departments themselves also have idiosyncratic features such as the "no criticism zone" of the mathematics department at St. Mary's College, MD (Kung, personal communication, July 27, 2017), which prescribes that faculty members should never publicly criticize students. Thus, while it is possible to gain deep insight into a department based on its disciplinary identity, it is important to consider other contextual factors that may impact the departmental culture when initiating a department-level change initiative.

There is evidence already that factors affecting change in education vary across disciplines (Matz et al., 2018). For example, a study of 10 STEM departments in the early stages of a university-wide effort to shift instructional practice identified both barriers and drivers for change (Shadle et al., 2017). While many barriers and drivers were present across departments, the relative frequency of their mention by faculty members differed by department, indicating that departments at a single university can have disparate cultures and benefit from distinct approaches to support sustainable change. There is also variation across DBER disciplinary fields, which has resulted in calls for more interdisciplinary collaboration and cooperation to understand what can and cannot be translated across disciplines to accelerate change in STEM education more broadly (Henderson et al. , 2017). Our work is part of this interdisciplinary DBER movement as we consider convergent and divergent aspects of culture among STEM disciplines. Here, we explore similarities and differences among STEM disciplinary cultures using the theoretical lens of four frames (structures, symbols, power, and people) for systemic change.

\section{THE TRUSE 2017 CONFERENCE Participants and Setting}

Data for this exploratory study were collected during the TRUSE conference held in July 2017 at the University of St. Thomas in St. Paul, MN. The goal of the TRUSE conference was to integrate DBER across STEM fields by networking DBER scholars from different disciplines together at the same conference. The meeting was attended by approximately 100 DBER scholars, primarily in the disciplines of biology, chemistry, mathematics, and physics, with a few participants from other fields such as psychology. Because of the focus of the meeting, most attendees were from research-intensive institutions.

\section{Sessions and Data Sources}

Data for this paper were collected from two sessions at the conference, and IRB approval was received for all research we report on. The first was a 1-hour plenary session focused on an introduction to the four frames and their application to systemic change. During that session, participants were given a brief survey (see the Supplemental Material) asking them to describe their disciplines according to the four frames model. A total of 78 participants from a variety of disciplines (Table 1) responded anonymously to the prompts using a Google Form (i.e., an online survey). All participants at the conference were 
TABLE 1. Self-identified disciplines of respondents to the plenary survey

\begin{tabular}{lcc}
\hline Discipline & Number of respondents & Percent of respondents \\
\hline Biology $^{\mathrm{a}}$ & 12 & 15 \\
Chemistry $_{\text {Mathematics }}$ & 28 & 36 \\
Physics & 13 & 17 \\
Total & 25 & 32 \\
\hline
\end{tabular}

Includes three respondents who listed anthropology, biochemistry, and entomology.

expected to be present at the session; the majority of those present responded to the survey. The original purpose of this data collection was for formative feedback on the conference session, not a full research study. However, we found that the perspectives offered by conference participants were valuable, and so we chose to analyze them as a preliminary form of data and potential precursor to more robust empirical studies.

The second session was a 90-minute follow-up breakout discussion targeted more specifically at disciplinary culture. This session was run parallel to a number of other breakout sessions, so the participants in this session were those who chose this particular session out of interest as a follow-up to the plenary. This session was designed to have participants think about the four frames in more depth and in a small-group setting. Participants $(N=36)$ were spread across the four disciplines listed in Table 1, with one additional participant from geology.

Participants were divided into seven small groups, each composed of members from a variety of disciplines so that participants could compare and contrast their disciplines. In this session, the participants continued to describe their disciplines using the four frames, generating posters about disciplinary similarities and differences. After participants generated group posters, a gallery walk format was used so that participants could interact with each poster. Participants used free-form comments as well as positive and negative check marks to indicate agreement or disagreement, respectively, with comments on the posters. Afterward, a session-wide discussion ensued.

The data from this exploratory study have not been made available to the public.

\section{Identifying Themes}

Our initial analyses consisted of R.L.M. and R.C. working independently with the data to generate impressions and categorize the responses according to the research question: How are the cultures of individual STEM disciplines both similar and different? R.L.M. worked primarily with the plenary session (survey) data, while R.C. worked primarily with the breakout session (poster) data. Each data set was reviewed and coded line by line into groups within each frame, creating new groups and reorganizing them as needed (Charmaz, 2006). Then, D.L.R., R.C., and R.L.M. collectively reviewed these interpretations and came to an agreement over what was represented in the data.

Throughout this process of viewing the data from multiple disciplinary perspectives, we met regularly to reconcile the nature of our approach. For example, we looked for the repetition of ideas; if a statement was provided multiple times in the plenary data, it was included in the analyses, but "one-off" comments were not included. Because responses on the posters represented a consensus of multiple individuals, they were included in the analyses unless other participants had challenged the responses; we note that many similar statements appeared across both the survey and poster data. After collaboratively reviewing our interpretations of the data, we began to write themes that summarized the groups of data and would eventually form the basis for our reported analyses.

Here, we provide an overview of responses as well as narrative descriptions of the most salient similarities and differences provided by respondents. Because respondents had limited exposure to the four frames, they occasionally miscategorized their responses. In the results, we associated these responses with our understanding of the appropriate frame. While institutional differences were not an explicit focus of the sessions, some emerged in the findings, so we speak to them as much as the data allow.

\section{DISCIPLINARY SIMILARITIES AND DIFFERENCES}

Meeting participants reported a variety of similarities (Table 2) and differences (Table 3) across disciplines in both the plenary and breakout session data. These data show some strong similarities between STEM disciplines. At the same time, the data suggest that unique disciplinary aspects may be lost in considering STEM disciplines as having a monolithic culture. To aid change agents working with STEM departments, we catalogue here the similarities and differences in disciplines noted by participants and describe how they might impact the design of a change strategy. To increase the likelihood of sustained adoption of educational innovations, it is important that change agents identify different aspects of the instructional system that are likely to impact propagation of an innovation (Stanford et al., 2016, 2017; Froyd et al., 2017).

\section{Similarities across Disciplines}

Respondents indicated that their disciplines had much in common (Table 2), which is consistent with typical perceptions of STEM disciplines. These similarities included structural aspects such as large introductory service courses with recitations or labs, and symbolic aspects such as the importance of subdisciplines and disciplinary representations. There were also similarities in terms of the types of roles people hold in academic departments and typical power hierarchies.

In general, respondents were consistent in their reporting of similarities across their disciplines. Nevertheless, there were two instances in which a single outlier described a feature as a difference, while others described it as a similarity. One of these instances related to introductory courses, with geology using introductory courses for recruitment but other disciplines viewing them as service courses that often function as "gatekeepers" for other majors. The other difference was a respondent who described a department as embracing constructivism, perhaps a local idiosyncratic difference and not a disciplinary feature, given the relative dominance of the transfer model of teaching reported by others.

\section{Structures}

Introductory Courses Are Most often High-Enrollment Service Courses. A common response in both the plenary and breakout session data across all disciplines was that introductory courses 
Structures

- Student numbers drive the lower-division curriculum.

- Introductory courses are typically high-enrollment service courses.

- Lab/design courses are associated with learning content and techniques (for disciplines that use labs).

- There are set topics in courses (canon) with some level of coordination for large, multisection courses.

- Faculty are expected to pursue and receive outside funding.

- Faculty members serve on a variety of committees (e.g., curriculum; reappointment, tenure, and promotion).
People

- Various roles include

- Chairs/administrators

- Tenure-track faculty

- Non-tenure track faculty

- Staff

- Postdocs

- Graduate students

- Undergraduate students

- People coalesce within subcultures (e.g., by subdiscipline, by senior vs. junior faculty status).
Symbols

- There are meaningful differences across subdisciplines.

- The discipline has a reputation as, e.g., rigorous, inaccessible, hard, or abstract.

- Faculty prioritize needs of 1) own students, 2) closely overlapping students, and 3) other students.

- Instructors have common beliefs about teaching:

- Teaching is an individual endeavor.

- Instructors have pedagogical autonomy.

- Instruction should focus on knowledge acquisition.

- The transfer model for teaching dominates.

- Introductory courses are gatekeepers.

- There is an extensive use of representations and symbolic manipulations.

Power

- White men tend to have the most power.

- Research status (grants and publications) leads to departmental status (e.g., in terms of teaching assignments).

- There are academic hierarchies:

- Research prestige over teaching

- Traditional areas of research over DBER (some institutional variation)

- Tenured over tenure-track over non-tenure track faculty

- Faculty over staff

- Seniority

- Subdisciplines compete for status. must accommodate large student enrollments with a "'pack 'em in' model limited only by the number of seats in the room," though participants said that, to some degree, this depends on the institution. Physics participants noted that though class sizes are large, graduate students usually run recitations in smaller sections, and this is often the case in chemistry and biology as well. It was also noted that "more advanced courses become more intimate" and that sometimes majors have their own smaller sections of introductory courses. Further, many participants discussed that the student population in these courses is composed primarily of nonmajors, which can lead to issues with nondepartmental majors influencing the curriculum. For example, a chemistry participant said that introductory chemistry courses (i.e., general and organic) can either be separate for pre-health students and majors or "a course for both majors must be broad to incorporate goals for both types of students."

Lower-Division Courses Often Use a Common Curriculum across Sections. Large-enrollment courses usually require multiple sections to facilitate scheduling and fitting students into classrooms, and many participants discussed the use of coordinated, common curricular materials across course sections. The degree of alignment across sections seemed to vary, with chemistry and mathematics participants often citing common syllabi, homework, and exams, and physics participants citing a required common textbook, "committee governance for large classes with multiple instructors," and a codified "canon of what topics

TABLE 3. Differences across disciplines

Structures

- Course ownership (by individuals vs. divisions vs. department)

- Structure of department (existence of divisions vs. no divisions)

- How teaching assignments are made (research/subdisciplinary specialty vs. general)

- The existence of developmental courses (mathematics vs. others)

- How upper-level courses are sequenced

- How first-year placement exams are used

- Level of collaboration in research

- Department management

People

- Gender balance

- Balance between tenure-track and non-tenure track faculty

- Support staff (e.g., for labs)

- Role of graduate students

- Responsibility for service courses (tenure-track faculty vs. lecturers vs. adjuncts)

- Presence or absence of professors of practice/teaching
Symbols

- Attitudes toward the discipline-perception as elite (mathematics, physics, chemistry)

- Emphasis on theoretical vs. empirical

- Focus of pedagogy (content knowledge vs. application)

- Teaching of models, theories, and certainty

- Who is prioritized beyond own students/majors

- Role of technology in supporting learning

Power

- Hierarchies between subdisciplines. Some disciplines noted "pure" research as more prestigious than "applied" (e.g., math), while others were the opposite (e.g., chemistry). 
go in which course." Breakout session participants agreed that a related, common issue in these courses is dealing with pre- and corequisite sequencing issues. For example, a change to the order of introductory biology courses would likely affect enrollments in prerequisite general chemistry courses.

Common Expectation to Pursue and Maintain External Funding. Issues related to research, particularly securing outside funding, appeared consistently throughout both the plenary and breakout session data and across all four frames. Participants discussed the typical expectation that faculty maintain externally funded research groups with the ability to pay graduate student research assistants and other personnel from grants. Participants also discussed how inconsistent or declining external funding affects not only the individual faculty member (e.g., teaching responsibilities may be increased), but also the department or unit as a whole (e.g., teaching assignments can become more tenuous). Research activity and, in particular, obtaining outside funding are highly valued by colleagues and seen as contributing to prestige. While the participants at the conference were primarily from research-intensive universities, a disproportionate emphasis on research is common even at primarily undergraduate colleges and universities, though the expectations for external funding are not as high.

\section{Symbols}

Differences across Subdisciplines Are Meaningful. Across all of biology, chemistry, mathematics, and physics, participants agreed that meaningful differences exist between subdisciplines. For example, participants discussed "biochemistry versus physical chemistry," "experimental versus theoretical physics," "pure versus applied" (from a mathematics participant), and that "biology is fragmented rather than a single discipline that has any consensus." Sometimes the subdisciplines (e.g., experimental and theoretical physics) were noted as complementary, but in other comments, the participants either implied or stated a difference in rank among subdisciplines. For example, both chemistry and physics participants discussed a perception that interdisciplinary chemistry and physics are not as "pure" as, respectively, research at the molecular level and "traditional" physics, in which models for understanding phenomena are very precise. Respondents also described the organizational role that subdisciplines play in departments in terms of formal structural divisions, creating subgroups of people, and in power hierarchies. These responses highlight that, while each discipline may have relative similarities in its culture, it is also important to consider existing subcultures.

Beliefs about Teaching. Across the disciplines, participants reported common beliefs about teaching such as valuing pedagogical autonomy, believing in "personal empiricism" (anecdotes), and teaching as an individual endeavor, focusing on knowledge acquisition and behaving as a "sage on the stage." In valuing autonomy, participants discussed that faculty often do not want to teach the same things or teach the same ways as one another, regardless of what that means for students earning the same credit in different sections of a course. Individual beliefs and anecdotes tend to limit productive discussions about teaching and learning; one participant put it succinctly that faculty can be "evidence-based except when it comes to teaching." Further, in some departments, there is little formal discussion of teaching at all, based in part on the faulty assumption that knowing a subject is all that is required to teach effectively.

\section{People}

Most Departments Have a Similar Mix of Roles. Respondents across both the plenary and breakout session data reported a typical mix of roles in their departments regardless of discipline: department chairs and other administrators, traditional tenure-track faculty, non-tenure track faculty, support staff, postdoctoral research associates, and graduate and undergraduate students. The non-tenure track faculty group seemed to exhibit the widest variation, with many types of roles fitting this category. Functionally, these roles include stable and contingent teaching faculty, clinical faculty, and research faculty, although the associated particular job titles, affordances, and constraints appear to be institution (rather than discipline) specific. A few participants specifically noted the presence of DBER faculty as a resource for ideas about improving teaching and learning, but the presence of DBER faculty in departments was not a universal theme across disciplines in these data.

\section{Power}

What Levels and Courses Do Faculty Teach? Participants consistently reported that research-active faculty tend to teach upper-division and graduate-level courses, and fewer courses overall, while non-tenure track teaching faculty tend to teach introductory courses. Course teaching assignments are generally made using a "top-down model," in which graduate and upper-division undergraduate courses are assigned first, with lecturers, visiting faculty, and adjuncts "filling in" whatever teaching assignments remain. As research faculty secure more external funding, they are "released" from teaching courses, and as a research group "winds down," the principal investigator is often subject to an increased teaching load. Participants also reported higher teaching loads for faculty teaching lower-division courses and that a consistent "churn" of instructors through introductory courses can make course improvements and pedagogical changes at scale difficult.

Social Identity Can Affect Who Has Power in a Department. Participants across disciplines reported that different aspects of social identity can affect who has power in a department, and these data were particularly centered on gender, race/ethnicity, and age. Mathematics and physics participants were straightforward, with comments like "mathematics is a highly masculinized, white endeavor" and "physicists must code male and masculine as much as possible," implying that physicists who are women or gender nonconforming (e.g., not appearing or "coding male" in a traditional masculine way) face barriers of not being welcome in the field. Additionally, a chemistry participant noted that women instructors may not be taken as seriously as men. Seniority was also discussed as an influence on power, with older faculty sometimes being "stuck in their ways" and having the ability to "shut down" younger faculty who are open to new ideas. A mathematics participant wrote that visible social markers (e.g., race and 
gender) may also be a source of prejudice against particular faculty members.

Tenured Faculty Are Most Highly Regarded in the Academic Hierarchy. Participants consistently reported across all disciplines that people with formal administrative roles, external funding, and tenure have the most power and agency in departments, followed by tenure-track faculty, continuing non-tenure track faculty, adjuncts and staff, and students. One participant went so far as to write that both students and staff have "no power," and others wrote that graduate students can have trouble adopting innovative teaching methods because of pushback from course instructors. Because it is common for non-tenure track instructors and "lower-status" faculty to teach introductory courses, instructors may limit innovative teaching methods to help ensure that students do not complain and that "service courses do not become a problem." Despite being close on the perceived "hierarchy," a mathematics participant wrote that "tenured faculty even exert influence over not-yet-tenured faculty," and a physics participant noted that "you earn your right to power by getting tenure and being top in your research field, not by considering students."

Research Is Valued over Teaching. Consistently across disciplines, participants reported that research is valued over teaching in terms of awards, job security, reputation, and even personal wealth. A biology participant described, for example, how research universities compete for faculty with medical schools and research institutes, which have very low or nonexistent teaching loads, so there is competition for teaching loads at universities to be correspondingly low. Others described teaching as something that faculty only need be "competent" at, whereas in research they have to be "stellar," and that how few courses someone teaches is an indirect measure of their research prowess. A mathematics participant offered the interesting comment that teaching lower-division courses as a service department is merely the "price we pay for bigger departments with more hiring lines," meaning that because mathematics departments serve so many nonmajors, they are able to hire more faculty to cover this high teaching load.

Subdisciplines Compete for Status. Many participants reported implicit competition among subdisciplines for prestige (e.g., experimental and theoretical physics) and, because of the nature of the TRUSE conference participants, the vast majority of these comments included comparisons involving DBER. Though some institutional variation was noted, most comparisons ranked DBER researchers and scholarship as less powerful than more traditional subdisciplines. Participants cited DBER scholars being perceived as "just there to help with teaching" and reported confusion about why a faculty member in DBER would need to have a research group with graduate students. Some participants noted the close relationship between DBER and social sciences contributing to a perception that education research is "easy and without standards of practice." Despite a lack of understanding about how DBER faculty conduct research, the national conversation about the importance of STEM education and scientific literacy has provided some pathways for DBER faculty positions.

\section{Differences across Disciplines}

Participants also noted moderate to substantial differences across disciplines according to the four frames (Table 3). For instance, participants described structural differences in how courses were assigned and whether certain faculty members had "ownership" over courses, as well as symbolic differences related to beliefs around teaching in courses. Participants noted differences in the representation of department members from different groups (e.g., by gender) and that power hierarchies between pure and applied fields may differ by discipline. Participants further noted some differences that they later decided through discussion were more likely to be institutional rather than disciplinary.

\section{Structures}

Background Required and Expectations for Teaching Assignments. In some disciplines, teaching assignments are frequently based on subdisciplinary expertise. The area of preparation (e.g., organic chemistry) for a particular instructor would typically define what courses he or she would teach, though the first-year introductory course could be taught by anyone in the department. That is, only organic chemists would typically teach organic chemistry. Mathematics faculty reported similarly that "PhDs and doctorates are valued over MS degrees" and that some tension exists around faculty crossing subdisciplinary boundaries to teach (e.g., "Do mathematicians have the philosophical background to teach statistics?" "Is statistics even considered a part of mathematics?"). In contrast, in both breakout and plenary session data, participants reported that physicists "are expected to be able to teach any core undergrad course," and furthermore, that they typically rotate through these courses, corroborating prior work (Chasteen et al., 2015). A cheeky participant who identified as a chemist wrote that "unlike physicists, chemists do not (and should not) teach any and all of the courses in their undergraduate curriculum." Relatedly, some breakout session participants noted their experience that chemistry and biology courses tend to be owned by individuals or divisions, while physics courses tend to be under broader departmental control, though participants also expressed that this varies by institution.

Level of Collaboration between Faculty. The degree to which faculty collaborate with one another in research projects appeared to differ somewhat by discipline. Biology faculty reported their discipline as "very collaborative" and "inherently collaborative," whereas chemistry and physics faculty described a wider range of behavior. Chemistry faculty reported collaboration "in small groups" and within various branches of chemistry, but fewer cross-disciplinary collaborations. Physics faculty reported that "both large collaborations and single investigator modes exist" and cited cross-disciplinary collaborations with engineering departments. Mathematics faculty primarily discussed working "as individuals, not in teams" and in "low collaboration" environments, corroborating a study of coauthorship networks that found mathematics papers to have the smallest average number of authors in comparison with biology and physics (Newman, 2004).

Curriculum. Participants perceived less course sequencing in upper-division chemistry and biology courses than in 
mathematics and physics courses. Mathematics was described as exhibiting a number of pedagogical and curricular differences compared with science disciplines: mathematics plays a large role in $\mathrm{K}-12$ education, placement exams are typical, mathematics departments often offer developmental or precollege courses, and many science courses are associated with corresponding laboratory courses, while this is rarely, if ever, the case for mathematics courses.

\section{Symbols}

Disciplinary Perceptions. Faculty reported different perceptions and realities for their disciplines, with biology and chemistry comments being somewhat similar and mathematics and physics comments being somewhat similar. A biology participant reported, for example, "math anxiety" and a "social perception that biologists are not good at math," and a chemistry participant reported that instructors "often use complex mathematical concepts and processes but do not have the background or depth of understanding to communicate them well when students have questions or get stuck." In contrast, mathematics participants reported the perception that "math knowledge and intelligence is still largely treated as innate" and a myth that "age and gender make a difference, i.e., if you haven't proven anything significant before age 25, you never will." Physics participants similarly reported belief in the "innate genius of practitioners," a "physics trumps all" mentality, a self-perception of being elite, and that "physicists are smart and know everything, and also know everything about education."

Empirical and Theoretical Considerations. Biology and chemistry participants almost unanimously reported that empirical evidence is most highly valued in these disciplines, whereas physics respondents more consistently referred to both "empirical and theoretical" subdisciplines. Pure mathematics stood out as a deductive, rather than empirical enterprise, with mathematics participants reporting that "theory trumps practice," "deductive reasoning is most important," and that "capital T truth (via logical succession) is how mathematicians identify results." Similarly, breakout session participants reported differences across disciplines in the nature of representations, whether the laboratory is central to student learning, and teaching about models, theories, and certainty, all of which reflect how theoretical and empirical work can be valued differently.

Pedagogy. Pedagogies that are valued in each discipline were reported to differ in some ways. For example, biology participants reported "lots of emphasis on memorizing the material and not much emphasis on application," and they emphasized the importance of the discipline being "jargon heavy." Chemistry participants noted that courses "focus on chemistry knowledge that benefits chemistry majors" but such knowledge may not be pertinent to nonmajors, and physics participants noted that conceptual understanding is valued only when "accompanied by significant symbolic manipulation or rigorous experimentation." Mathematics participants emphasized "objective grading through focusing on computational procedures and final answers" and an "aversion to technology," stating that students should not be able to use calculators in lower-division courses.
Specific Models, Frameworks, Languages, and People. Participants from the different disciplines naturally cited specific frameworks, models, languages, and people particular to the area of study, such as triangulating between macroscopic, microscopic, and symbolic representations (Johnstone's triangle) in chemistry; and a reductionist approach (i.e., toy models and the spherical cow) in physics. Physics participants also repeatedly cited a "myth of 'heroes' (e.g., Newton and Einstein)," the "great man/ lone genius model," and a "creepy devotion to a 'great men' mindset." Breakout session participants identified physics and chemistry, and mathematics to a lesser extent, as having a "weapons history" but recognized that faculty in all disciplines have to consider the ethics of their work.

\section{People}

Instructor Roles. The biology, chemistry, and physics participants in near unanimity reported that graduate students teach laboratory sections and recitation sections for lecture courses and that sometimes they serve as teaching assistants (TAs) for upper-division or graduate-level courses. Rare exceptions included "teaching upper-level laboratories" (chemistry participant) and teaching "intro courses over the summer, or during Fall/Spring if there are funding shortages for faculty" (physics participant). In contrast, mathematics participants reported that graduate students often teach service courses as instructors of record, though "even this group is extremely diverse in that we have young master's students who have just finished their bachelor's and have no teaching experience, and we also have fourth-year math education PhD students who may already hold a master's in teaching and have years of experience in the classroom as an instructor and student of pedagogy."

Demographic Variation. Differences in the representation of women in the disciplines were reported in both the plenary and breakout session data. Biology was reported as being "much more gender balanced," while physics was described as being both "all white/male" and as having a "large percentage of international faculty." Mathematics was also reported as being male dominated, with chemistry falling somewhere in between. Differences in the ratio of tenure-track to non-tenure track or contingent faculty also emerged in the breakout sessions, although details were not provided as to which disciplines have a higher ratio. It is our perception that mathematics tends to make the highest use of contingent faculty.

Power. Power is the one frame in which clear differences between disciplines did not arise. One tentative idea mentioned in both the plenary and breakout sessions is that some disciplines, such as mathematics, value "pure" research over applied research, while this was not observed in other disciplines. There were also reported differences in how decisions get made in departments, but these appeared to arise from institutional rather than disciplinary differences.

\section{RECOMMENDATIONS FOR CHANGE STRATEGIES}

These preliminary findings have potential implications for designing and implementing change strategies. Given the tentative nature of this study, we provide provisional recommendations for change agents. Participants across the disciplines reported a number of similarities regarding instruction in their 
TABLE 4. Disciplines characterized by frame

\begin{tabular}{|c|c|c|c|c|}
\hline & Biology & Chemistry & Physics & Mathematics \\
\hline Structures & $\begin{array}{l}\text { Very/inherently } \\
\text { collaborative research } \\
\text { - Courses are somewhat un } \\
\text { sequenced }\end{array}$ & $\begin{array}{l}\text { Groups of collaborative } \\
\text { researchers, primarily } \\
\text { within branches of } \\
\text { chemistry } \\
\text { - Subdiscipline affects what } \\
\text { courses someone can } \\
\text { teach }\end{array}$ & $\begin{array}{l}\text { Varied levels of collabora- } \\
\text { tion, some with } \\
\text { engineering } \\
\text { - Any faculty member can } \\
\text { teach any introductory } \\
\text { course }\end{array}$ & $\begin{array}{l}\text { - } \text { Individual research } \\
\text { - } \text { Courses are highly } \\
\text { sequenced } \\
\text { - } \text { Moderate impact of } \\
\text { background on teaching } \\
\text { assignments } \\
\text { - No/few laboratories }\end{array}$ \\
\hline Symbols & $\begin{array}{l}\text { Mathematics anxiety/ } \\
\text { perception that biologists } \\
\text { are not good at math } \\
\text { - Value of empirical } \\
\text { research } \\
\text { - (Generally) an emphasis } \\
\text { on memorization }\end{array}$ & $\begin{array}{l}\text { Value of empirical } \\
\text { research } \\
\text { - Introductory courses } \\
\text { designed for chemistry } \\
\text { majors } \\
\text { - Coordinating macro- } \\
\text { scopic, microscopic, and } \\
\text { symbolic representations } \\
\text { - Weapons history }\end{array}$ & $\begin{array}{l}\text { - Innate and lone genius of } \\
\text { physicists } \\
\text { - Physics trumps all other } \\
\text { fields } \\
\text { - Conceptual understand- } \\
\text { ing only valuable if } \\
\text { accompanied by } \\
\text { procedural skill } \\
\text { - Reductionist approach } \\
\text { - "Hero worship" } \\
\text { - Weapons history }\end{array}$ & $\begin{array}{l}\text { - Mathematical ability/skill } \\
\text { is innate and present at } \\
\text { an early age } \\
\text { - Deductive/inductive } \\
\text { reasoning valued over } \\
\text { empirical data } \\
\text { - Aversion to technology }\end{array}$ \\
\hline People & $\begin{array}{l}\text { - Graduate students teach } \\
\text { labs and recitations }\end{array}$ & $\begin{array}{l}\text { - Graduate students teach } \\
\text { labs and recitations }\end{array}$ & $\begin{array}{l}\text { - Graduate students teach } \\
\text { labs and recitations }\end{array}$ & $\begin{array}{l}\text { - Graduate students are } \\
\text { commonly instructors of } \\
\text { record for introductory } \\
\text { courses }\end{array}$ \\
\hline Power & & No differences reported & & $\begin{array}{l}\text { - Pure mathematics more } \\
\text { "important" than applied }\end{array}$ \\
\hline
\end{tabular}

disciplines: instructors have pedagogical autonomy, instruction is teacher-focused, and early courses play a gatekeeping role. These beliefs reflect the views of faculty members who are content experts and who appear to desire considerable control over teaching and learning in their courses (Reinholz et al., 2019a). For this reason, it is important to give faculty some ownership in any change process. Change imposed on faculty is not likely to be successful. Instead, faculty should be active participants in learning about and adopting new ways of teaching (Quan et al., 2019).

At the same time, the participants described a number of differences that we conjecture have important implications for change efforts. We recognize that other viable recommendations can be made from these data but have limited this discussion to maintain brevity. To highlight how change agents might approach and involve particular disciplines differently, we organize the differences from the previous section into tables by frame and discipline (Table 4). We do not suggest that this is a conclusive or fully accurate depiction of the culture of each discipline, rather that it provides an adequate basis for future work. These preliminary data and analyses suggest that these disciplines have meaningful structural and symbolic differences. The most notable differences in the people frame concern the role of graduate students, with mathematics being distinct from other STEM fields. Power dynamics do not appear to differ appreciably by discipline. Here, we describe two potential strategies as related to three of the four frames: structures, symbols, and people.

\section{Background Required and Expectations for Teaching Assignments (Structures)}

Of particular interest in the structural frame is the nature of how teaching assignments are made with respect to the instruc- tor's disciplinary background. Physics stands out as a discipline in which faculty are expected to be able to teach across the undergraduate curriculum regardless of their particular research areas or graduate school training, and they regularly rotate through different courses (Matz et al., 2018). This expectation might lead to different-perhaps more collaborative and distributed-structures for course ownership in physics compared with biology, chemistry, and mathematics and would differentially impact efforts to change physics curricula. For instance, compared with other STEM departments participating in the Science Education Initiative, the physics department at the University of Colorado-Boulder made some of the most extensive revisions to the learning goals and teaching techniques used in its courses, and the frequent rotation of faculty members was cited as one relevant supporting factor (Chasteen et al., 2015). However, it also means that sustained changes to instruction in a given course require support from the majority of the department rather than a subset of faculty; curricular changes might therefore take more time to implement in physics than other disciplines.

In disciplines with a stronger culture of stable teaching assignments based on subdisciplines, it might be necessary to consider the approaches and expectations of faculty who traditionally teach a narrower range of courses. For example, a change agent might need to consider specific differences between organic chemistry and physical chemistry to ensure that a non-course specific approach would make sense to faculty in both contexts. In departments in which faculty are less likely to teach across the curriculum, it may also be harder for instructional approaches to spread across the department, because there may be fewer opportunities for "cross-pollination" through collaborations in teaching. This may require 
change agents to consider how to promote exchange of experiences and support if instructors are teaching different courses. This consideration is particularly important, as change efforts are more likely to succeed if they impact the culture of department as a whole, rather than being siloed within small parts of the department (Reinholz et al., 2019b).

\section{Level of Collaboration between Faculty (Structures)}

Participants noted how these STEM disciplines differ in terms of how collaborative the research tends to be. For instance, disciplines differ in how many authors are likely to be present on a single publication (Newman, 2004; Bozdogan and Akbilgic, 2013); some collaborative physics research is conducted in immense research teams, including, for example, more than 5000 authors on a single paper (Aad et al., 2015). Given that disciplines such as physics, biology, and chemistry may be more collaborative in research, it may be easier to translate these types of collaborations to the settings of teaching, learning, and institutional change. In contrast, mathematics (especially pure mathematics) tends to be less collaborative, so additional effort may be required to build collaborations between mathematicians in a department. This pattern suggests that change efforts in mathematics departments may need to invest additional effort into building collaborative structures, whereas other STEM departments may have more access to leveraging existing structures and collaborative habits.

\section{Disciplinary Perceptions (Symbols)}

The STEM disciplines differ considerably in terms of their societal perceptions. Both mathematics and physics are colloquially considered to be disciplines for "geniuses" (i.e., people having innate brilliance), which has been shown to reduce diversity in those fields (Leslie et al., 2015). The common myth that mathematicians must do their best work while young, or not at all (Hardy, 1940), reinforces a fixed mindset, which posits that intelligence is largely innate, rather than developed through hard work (Dweck, 2006). This perspective has serious pedagogical implications. From the fixed perspective, it is the job of an instructor to support the "strong" students to be successful while simultaneously "weeding out" the weaker students. This ideology is largely inconsistent with research in STEM education reform and equity (Ladson-Billings, 1995). Yet, because of the prominence of these ideologies in fields that have ingrained narratives about brilliance, educational change will require grappling with these deeprooted ideas about how students learn, and who can learn mathematics or physics. These perceptions imply that an effort to introduce new teaching practices in physics or mathematics might need to be paired with a corresponding effort to change perceptions about students, the nature of learning, and narratives about intelligence.

\section{Empirical and Theoretical Considerations (Symbols)}

A noted key difference in terms of symbols is that pure mathematics is deductive rather than empirical, indicating that how mathematicians think about evidence at the disciplinary level appears to be unique within STEM. Mathematicians talk about ideas such as "existence proofs" for change or wanting irrefutable evidence, whereas those in science disciplines may be better positioned to think about the nuances of data collection and analysis, because empirical study is part and parcel of what they do in their everyday work. These differences might have implications for change efforts, because mathematics departments may respond to evidence (or even data-driven design) differently than science departments. Research on persuasion shows that the influence of evidence on beliefs is situational (i.e., under some circumstances, individuals are more likely to be convinced by evidence rather than other factors), suggesting that the value attributed to empirical evidence may reasonably differ by discipline (Petty et al., 1981; Petty and Cacioppo, 1986). Another unique factor of mathematics departments is their emphasis on "problem solving," which may make them less likely to engage with change processes focused on generating shared visions for an outcome to be achieved, in contrast with the more typical view of finding problems and making sure they are addressed (Reinholz et al., 2019c). These differences indicate that it may be useful for change agents to determine what would serve as necessary and sufficient evidence to encourage instructors in a department to change their instructional practices.

\section{Instructor Roles (People)}

One commonality across the STEM disciplines surveyed is that they tend to have large-enrollment introductory courses. These courses serve a large number of students, both majors and nonmajors. They also serve as an entry point into STEM majors and so play a critical role in student persistence (PCAST, 2012). For these reasons, change in introductory courses can have a large impact (Matz et al., 2018), which is why these courses are a typical focus for change efforts. Finally, introductory courses often have some structure for coordination across multiple sections with multiple instructors, graduate TAs, and undergraduate learning assistants. A coordination structure is a powerful leverage point for supporting collaboration and sustainability of educational improvement, because the change does not reside in the practice of a single individual (Mestre et al., 2019).

However, differences in who is assigned to teach these courses could reasonably impact the selection of appropriate change strategies. Graduate students in science disciplines tend to teach discussion or laboratory sections of large-enrollment courses; graduate students in mathematics are more likely to be the instructor of record for one or more sections of a multisection introductory course. This practice has implications for the degree and nature of TA training required for sustained changes in instructional strategies and affects who has the authority to make decisions regarding instructional practice. Graduate and undergraduate students teaching laboratory sections generally have very little voice in curricular decisions and primarily focus instead on supporting and monitoring students. This suggests that changes in laboratory instruction, particularly in institutions that rely on TAs, must consider issues related to TA training and buy-in in addition to supporting instructors. For changes that would primarily impact discussion, change agents must determine their target audience (course instructors, TAs, both) and the differing ways to reach and support them. In cases in which graduate students are the instructors of record, in addition to convincing them to adopt strategies, support must also be provided to ensure that these adopters will have buy-in from others with more power in the department. Departments must also have 
adequate resources to provide appropriate professional development opportunities for these novice instructors to effectively implement evidence-based strategies where they are responsible for more aspects of the course.

\section{Demographic Variation (People)}

While all of the STEM disciplines struggle with diversity in both the faculty and student populations, some disciplines struggle more than others. For example, there are considerably more women faculty in the life sciences as compared with the physical sciences or engineering (National Academy of Sciences, 2007). At the same time, research shows that, when instructors and students are aligned according to a variety of demographic characteristics such as gender and race, it improves student outcomes (Dee, 2004) and experiences (Egalite and Kisida, 2018). When students have instructors who are more "like them," this provides them with instructors who can more easily serve a role models and who also are more likely to understand the particular racialized or gendered experiences of the students.

Given the general lack of diversity in STEM, this systemic problem creates a challenge for supporting and diversifying the population of STEM students. This problem will be especially profound in disciplines such as engineering and computer science, where there is striking homogeneity in the faculty population, and suggests that additional effort around training to recognize implicit bias and develop cultural competence may be needed to support faculty learning in such disciplines. While similar development would still be beneficial, for instance, in a life sciences department, building on the existing (relatively greater) diversity provides an entry point for working with students.

\section{LIMITATIONS}

These results, as noted previously, are based on comments from a self-selected group of DBER researchers who attended the TRUSE conference. While our respondents were relatively evenly spread across certain STEM disciplines, we did not have respondents from all disciplines (e.g., computer science, all of the earth sciences, and the array of engineering disciplines), so we do not claim that these findings represent all STEM disciplines. Given that our data were collected primarily from DBER scholars at a research-focused conference, our sample is further biased toward research-intensive institutions and faculty with a deep interest in teaching and learning. There are also limitations to the poster data: handwritten comments were interpreted out of the context of the group discussions (though with the aid of field notes), and one differences poster was lost in data collection.

There are also ideas for which we have data from members of some disciplines but not all (e.g., the extent to which introductory courses are sequential). These notions of disciplinary differences suggest the utility of future work to better catalogue differences and similarities in disciplinary cultures and to investigate the implications of those differences in relation to teaching, learning, and change in STEM fields. Thus, we acknowledge that these are preliminary results, not intended to reflect a full study. For these reasons, the generalizability of our findings is limited. Still, we contend that these are compelling data that provide grist for future research, and we provide examples of questions that would support such research in Table 5. We elaborate these future directions in the following section.

In addition to disciplinary differences, it emerged through discussions and notes on the posters that some differences were likely institutional or departmental in addition to disciplinary. The institutional differences noted by participants included: course ownership, use of placement exams, collaboration, departmental management, and the existence of teaching professors (or professors of practice). This list is far from exhaustive, because institutional differences were not the focus of the session. Nevertheless, the brief discussions from participants highlight that institutional differences are an area of focus for future work.

\section{RECOMMENDATIONS FOR RESEARCH}

As suggested by our results, the STEM disciplines surveyed in this paper appear to share a variety of common characteristics. At the same time, there are also apparent differences across disciplines that warrant deeper investigation. For instance, a change agent who is familiar with mathematics may be surprised to encounter the somewhat more collaborative nature of a biology department, the specific subdisciplines of chemistry, or the rotation of faculty teaching courses in physics. We provide a short sample of preparatory questions in Table 5 to help change agents work across disciplines and probe departmental context and culture.

TABLE 5. Questions for understanding disciplinary culture

\author{
Structures \\ What are the teaching loads? \\ Who "owns" courses? \\ What types of courses exist? \\ How does recruitment take place? \\ How often do people meet? \\ What are the committee types/structures? \\ People \\ Who are typical students in the major? \\ What is the role of TAs? \\ Who teaches introductory courses? \\ What is the diversity of faculty? \\ What are the goals of students/faculty? \\ What is the nature of collaboration?
}

\section{Symbols}

What subdisciplines exist?

What societal narratives exist?

What is the view of intelligence/learning?

Are there standards or accrediting bodies?

Is the work empirical/deductive/design?

What are the disciplinary settings?

Power

What is the status of subdisciplines?

What is the status of research vs. teaching?

Who gets to vote?

What is the role of "superstars"?

What is the status of education?

How do committees influence governance? 
In addition to supporting investigation of disciplinary differences, these questions might be used to understand more about departmental and institutional idiosyncrasies, support sustainable change by helping to uncover relevant aspects of culture, and thus support external change agents by helping them understand other departmental cultures. These questions can support internal agents by helping them better recognize the unique strengths of their own departments.

These preliminary findings suggest various productive areas for future research. For example, we have hypothesized a number of possible strategies that may work more or less effectively with particular disciplines, and it would be valuable to the community to more deeply explore the use of particular strategies in different disciplines. Apropos to this, we offer the following research questions:

1. Which change strategies work most effectively in particular STEM disciplines?

2. What would be required to leverage discipline-specific ways of thinking and change strategies that have been developed in one discipline to affect another discipline?

3. What change strategies are effective generally across disciplines yet customizable to the specific context of an individual disciplinary department?

\section{CONCLUSION}

This conference report provides three key insights. First, STEM disciplines cannot always be adequately treated as having a monolithic culture; these data highlight differences between disciplines that may have important implications for change efforts. While previous studies have contrasted STEM with the humanities and social sciences (Becher, 1994; Lee et al., 2007; Kezar, 2011), differences in the adoption of evidence-based teaching strategies have also been observed across STEM disciplines (Lund and Stains, 2015; Shadle et al., 2017). These and other studies have indicated the importance of considering the contexts that influence faculty decisions, including departmental culture. Our use of the four frames model pushes the field forward by elaborating some of the potentially meaningful differences between STEM disciplinary cultures. For any change agent interested in working with STEM departments, these analyses provide a starting place for considering the different disciplines they may work with and how their approaches to change might differ by discipline. Second, this work draws attention to some key ways in which disciplines are similar. Third, even without a full classification of different STEM disciplines, this paper suggests potentially useful questions for understanding departmental culture. These questions may be useful, because even with a general description of disciplinary culture and institutional types, further inquiry is always helpful, given the uniqueness of each department. This process of inquiry also plays a role in the change process, because it is a means of showing interest in a department and beginning to build trust within the local community.

\section{ACKNOWLEDGMENTS}

We thank participants at the 2017 TRUSE conference for their thoughtful responses to our questions. We also appreciate the feedback from anonymous reviewers of this article. This research was conducted without external funding.

\section{REFERENCES}

Aad, G., ATLAS Collaboration, CMS Collaboration. (2015). Combined measurement of the Higgs boson mass in $\$ p p \$$ collisions at $\sqrt{s}=7$ and $8 \mathrm{TeV}$ with the ATLAS and CMS experiments. Physical Review Letters, 114(19), 191803. https://doi.org/10.1103/PhysRevLett.114.191803

American Association for the Advancement of Science. (2011). Vision and change in undergraduate biology education: A call to action. Washington, DC.

Association of American Colleges and Universities. (2014). Achieving systemic change: A sourcebook for advancing and funding undergraduate STEM education. Washington, DC.

Austin, A. E. (2011). Promoting evidence-based change in undergraduate science education. East Lansing: Michigan State University.

Becher, T. (1994). The significance of disciplinary differences. Studies in Higher Education, 19(2), 151-161. https://doi.org/10.1080/03075079412 331382007

Blair, R. M., Kirkman, E. E., \& Maxwell, J. W. (2018). Statistical abstract undergraduate programs in the mathematical sciences in the United States: 2018 CBMS survey. Providence, RI: American Mathematical Society.

Bolman, L. G., \& Deal, T. E. (2008). Reframing organizations: Artistry, choice, and leadership. San Francisco: Jossey-Bass.

Borrego, M., \& Henderson, C. (2014). Increasing the use of evidence-based teaching in STEM higher education: A comparison of eight change strategies: increasing evidence-based teaching in STEM education. Journal of Engineering Education, 103(2), 220-252.

Bozdogan, H., \& Akbilgic, O. (2013). Social network analysis of scientific collaborations across different subject fields. Information Services \& Use $33(3-4), 219-233$.

Charmaz, K. (2006). Constructing grounded theory: A practical guide through qualitative analysis. Thousand Oaks, CA: Sage.

Chasteen, S. V., Wilcox, B., Caballero, M. D., Perkins, K. K., Pollock, S. J., \& Wieman, C. E. (2015). Educational transformation in upper-division physics: The Science Education Initiative model, outcomes, and lessons learned. Physical Review Special Topics-Physics Education Research, 11(2), 020110. https://doi.org/10.1103/PhysRevSTPER.11.020110

Chetty, R., Friedman, J. N., Saez, E., Turner, N., \& Yagan, D. (2017). Mobility report cards: The role of colleges in intergenerational mobility. Cambridge, MA: National Bureau of Economic Research.

Commonwealth of Australia. (2015). Vision for a science nation: Responding to science, technology, engineering, and mathematics: Australia's future (Consultation paper). Canberra, Australia.

Dee, T. (2004). Teachers, race and student achievement in a randomized experiment. Review of Economics and Statistics, 86(1), 195-210.

Docktor, J. L., \& Mestre, J. P. (2014). Synthesis of discipline-based education research in physics. Physical Review Special Topics-Physics Education Research, 10(2), 020119. https://doi.org/10.1103/PhysRevSTPER 10.020119

Dunne, E., \& Zandstra, R. (2011). Students as change agents-New ways of engaging with learning and teaching in higher education. Bristol, UK: A Joint University of Exeter/ESCalate/HE Academy Publication.

Dweck, C. (2006). Mindset: The new psychology of success. New York: Random House.

Egalite, A. J., \& Kisida, B. (2018). The effects of teacher match on students academic perceptions and attitudes. Educational Evaluation and Policy Analysis, 40(1), 59-81. https://doi.org/10.3102/0162373717714056

Elrod, S., \& Kezar, A. (2015). Increasing student success in STEM: A guide to systemic institutional change. Washington, DC: Association of American Colleges \& Universities.

European Parliament. (2015). Encouraging STEM studies for the labour market. European Union. Retrieved January 31, 2019, from www.europarl .europa.eu/studies

Fairweather, J. (2008). Linking evidence and promising practices in science, technology, engineering, and mathematics (STEM) undergraduate education. Washington, DC: Board of Science Education, National Research 
Council, National Academies. Retrieved January 31, 2019, from http:// otl.wayne.edu/wider/linking_evidence-fairweather.pdf

Freeman, S., Eddy, S. L., McDonough, M., Smith, M. K., Okoroafor, N., Jordt, H., \& Wenderoth, M. P. (2014). Active learning increases student performance in science, engineering, and mathematics. Proceedings of the National Academy of Sciences USA, 111(23), 8410-8415. https:// doi.org/10.1073/pnas.1319030111

Froyd, J., Henderson, C., Cole, R., Friedrichsen, D., Khatri, R., \& Stanford, C. (2017). From dissemination to propagation: A new paradigm for education developers. Change: The Magazine of Higher Learning, 49(4), 3542

Hardy, G. H. (1940). A mathematician's apology. Cambridge, UK: Cambridge University Press.

Henderson, C., Beach, A., \& Finkelstein, N. (2011). Facilitating change in undergraduate STEM instructional practices: An analytic review of the literature. Journal of Research in Science Teaching, 48(8), 952984

Henderson, C., Cole, R., Froyd, J., Friedrichsen, D., Khatri, R., \& Stanford, C. (2015). Designing educational innovations for sustained adoption: A how-to guide for education developers who want to increase the impact of their work. Kalamazoo, MI: Increase the Impact.

Henderson, C., Connolly, M., Dolan, E. L., Finkelstein, N., Franklin, S., Malcolm, S., ... \& St. John, K. (2017). Toward the STEM DBER Alliance: Why we need a discipline-based STEM education research community. International Journal of STEM Education, 4(14), 1-4.

Hurtado, S., Eagan, M. K., Tran, M. C., Newman, C. B., Chang, M. J., \& Velasco, P. (2011). "We do science here": Underrepresented students' interactions with faculty in different college contexts. Journal of Social Issues, 67(3), 553-579. https://doi.org/10.1111/j.1540-4560.2011.01714.x

Kezar, A. (2011). What is the best way to achieve broader reach of improved practices in higher education? Innovative Higher Education, 36(4), 235247. https://doi.org/10.1007/s10755-011-9174-z

Kezar, A. (2014). How colleges change: Understanding, leading, and enacting change. New York: Routledge.

Ladson-Billings, G. (1995). Toward a theory of culturally relevant pedagogy. American Educational Research Journal, 32(3), 465-491. https:// doi.org/10.3102/00028312032003465

Langan-Fox, J., \& Tan, P. (1997). Images of a culture in transition: Personal constructs of organizational stability and change. Journal of Occupational and Organizational Psychology, 70(3), 273-293.

Laursen, S. (2016). Organizational features that influence departments uptake of student-centered instruction: Case studies from inquiry-based learning in college mathematics. Paper presented at: Annual Conference for Research on Undergraduate Mathematics Education, Pittsburgh, PA

Lee, J. J. (2007). The shaping of the departmental culture. Journal of Higher Education Policy and Management, 29(1), 41-55. https:// doi.org/10.1080/13600800601175771

Lee, V. S., Hyman, M. R., \& Luginbuhl, G. (2007). The concept of readiness in the academic department: A case study of undergraduate education reform. Innovative Higher Education, 32(1), 3-18. https://doi.org/10.1007/ s10755-006-9032-6

Leslie, S.-J., Cimpian, A., Meyer, M., \& Freeland, E. (2015). Expectations of brilliance underlie gender distributions across academic disciplines. Science, 347(6219), 262-265. https://doi.org/10.1126/science .1261375

Levin, J. S. (2005). The business culture of the community college: Students as consumers; students as commodities. New Directions for Higher Education, 2005(129), 11-26. https://doi.org/10.1002/he.169

Lund, T. J., \& Stains, M. (2015). The importance of context: An exploration of factors influencing the adoption of student-centered teaching among chemistry, biology, and physics faculty. International Journal of STEM Education, 2(1), 13.

Matz, R. L., Fata-Hartley, C. L., Posey, L. A., Laverty, J. T., Underwood, S. M., Carmel, J. H., ... \& Cooper, M. M. (2018). Assessing the extent of a largescale transformation in gateway science courses. Science Advances, 4(10), eaau0554

Mestre, J. P., Herman, G. L., Tomkin, J. H., \& West, M. (2019). Keep your friends close and your colleagues nearby: The hidden ties that improve
STEM education. Change: The Magazine of Higher Learning, 51(1), 4249. https://doi.org/10.1080/00091383.2019.1547081

Mixon, S. L., Lyon, L., \& Beaty, M. (2004). Secularization and national universities. Journal of Higher Education, 75(4), 400-419. https://doi.org/10 .1080/00221546.2004.11772265

National Academy of Sciences. (2007). Beyond bias and barriers: Fulfilling the potential of women in academic science and engineering. Washington, DC: National Academies Press.

National Research Council. (2012). Discipline-based education research: Understanding and improving learning in undergraduate science and engineering. Washington, DC: National Academies Press. https:// doi.org/10.17226/13362

Newman, M. E. (2004). Coauthorship networks and patterns of scientific collaboration. Proceedings of the National Academy of Sciences USA, 101(suppl 1), 5200-5205.

Niss, M. (2011). The Danish KOM project and possible consequences for teacher education. Cuadernos de Investigación y Formación en Educación Matemática, 6(9), 13-24.

Petty, R. E., \& Cacioppo, J. T. (1986). The elaboration likelihood model of persuasion. In Petty, R. E., \& Cacioppo, J. T. (Eds.), Communication and persuasion: Central and peripheral routes to attitude change (pp. 1-24). https://doi.org/10.1007/978-1-4612-4964-1_1

Petty, R. E., Cacioppo, J. T., \& Goldman, R. (1981). Personal involvement as a determinant of argument-based persuasion. Journal of Personality and Social Psychology, 41(5), 847-855. https://doi.org/10.1037/0022-3514 41.5.847

President's Council of Advisors on Science and Technology. (2012). Engage to excel: Producing one million additional college graduates with degrees in science, technology, engineering, and mathematics. Washington, DC: U.S. Government Office of Science and Technology.

Quan, G. M., Corbo, J. C., Finkelstein, N. D., Pawlak, A., Falkenberg, K., Geanious, C., ... \& Reinholz, D. L. (2019). Designing for institutional transformation: Six principles for department-level interventions. Physical Review Physics Education Research, 15(1), 010141. https://doi.org/10.1103/ PhysRevPhysEducRes.15.010141

Quardokus, K., \& Henderson, C. (2015). Promoting instructional change: Using social network analysis to understand the informal structure of academic departments. Higher Education, 70(3), 315-335. https:// doi.org/10.1007/s10734-014-9831-0

Reinholz, D. L., \& Apkarian, N. (2018). Four frames for systemic change in STEM departments. International Journal of STEM Education, 5(1), 3 https://doi.org/10.1186/s40594-018-0103-x

Reinholz, D. L., Corbo, J. C., Bernstein, D. J., \& Finkelstein, N. (2019a) Evaluating scholarly teaching: A model and call for an evidence-based approach. In Lester, J., Klein, C., Johri, A., \& Rungwala, H. (Eds.), Learning analytics in higher education: Current innovations, future potential, and practical applications. New York: Routledge.

Reinholz, D. L., Ngai, C., Quan, G., Pilgrim, M. E., Corbo, J. C., \& Finkelstein, N. (2019b). Fostering sustainable improvements in science education: An analysis through four frames. Science Education, 103(5), 1125-1150. https://doi.org/10.1002/sce.21526

Reinholz, D. L., Pilgrim, M. E., Corbo, J. C., \& Finkelstein, N. (2019c) Transforming undergraduate education from the middle out with departmental action teams. Change: The Magazine of Higher Learning, 51(5), 64-70. https://doi.org/10.1080/00091383.2019.1652078

Schein, E. H. (2010). Organizational culture and leadership. San Francisco: Jossey-Bass.

Shadle, S. E., Marker, A., \& Earl, B. (2017). Faculty drivers and barriers: Laying the groundwork for undergraduate STEM education reform in academic departments. International Journal of STEM Education, 4(8), 1-13.

Singer, S. R., Nielsen, N. R., \& Schweingruber, H. A. (2013). Biology education research: Lessons and future directions. CBE-Life Sciences Education, 12(2), 129-132.

Sohoni, S., Craig, S. D., \& Vedula, K. (2017). A blueprint for an ecosystem for supporting high quality education for engineering. Journal of Engineering Education Transformations, 30(4), 58-66.

Stains, M., Harshman, J., Barker, M. K., Chasteen, S. V., Cole, R., DeChennePeters, S. E., ... Young, A. M. (2018). Anatomy of STEM teaching in North American universities. Science, 359(6383), 1468-1470. 
Stanford, C., Cole, R., Froyd, J., Friedrichsen, D., Khatri, R., \& Henderson, C. (2016). Design and development of a sustained adoption assessment instrument for characterizing effective propagation plans for STEM educational innovations. International Journal of STEM Education, 3(1), $1-13$.

Stanford, C., Cole, R., Froyd, J., Friedrichsen, D., Khatri, R., \& Henderson, C. (2017). Analysis of propagation plans of NSF-funded education development projects. Journal of Science Education and Technology, 26(4), 418-437.
Steinert, Y., Mann, K., Centeno, A., Dolmans, D., Spencer, J., Gelula, M., \& Prideaux, D. (2006). A systematic review of faculty development initiatives designed to improve teaching effectiveness in medical education BEME Guide No. 8. Medical Teacher, 28(6), 497-526. https:// doi.org/10.1080/01421590600902976

Talanquer, V. (2014). DBER and STEM education reform: Are we up to the challenge? Journal of Research in Science Teaching, 51(6), 809-819.

Warren, J. R. (1971). College grading practices: An overview. ETS Research Bulletin Series, 1971(1). https://doi.org/10.1002/j.2333-8504.1971.tb00423.x 